\title{
Peran Bimbingan dan Konseling dalam Penguatan Pendidikan Karakter di Sekolah Menengah Kejuruan
}

\author{
Muslihati Muslihati* \\ Jurusan Bimbingan dan Konseling, Fakultas Ilmu Pendidikan, Universitas Negeri Malang \\ Jl. Semarang No. 5, Malang, Jawa Timur, Indonesia, 65145 \\ *Penulis koresponden, e-mail: muslihati.fip@um.ac.id
}

Artikel diterima: 23 Maret 2019; direvisi: 21 Juni 2019; disetujui: 25 Juni 2019

\begin{abstract}
This research aims at describing the roles of guidance and counseling in strengthening character education of the students of Mitra Industri MM2100 Vocational High School, Cikarang, Bekasi, West Java. It used qualitative approach with case study design, in which the data was collected through interview and observation. The main informants were: coordinator of Mitra Industri Cikarang Foundation; principal; assistant principal of academic affairs and curriculum; dean of students; school counselor; homeroom teacher; and students of Mitra Industri MM2100 Vocational High School. The data was analyzed by category and reduction in accordance with the focus of the research. The results of the research show that guidance and counseling has important roles in strengthening the character education. guidance and counseling has active roles in the selection process; preventing deviant behaviors; and eradication of deviant behaviors in students. These roles are conducted collaboratively with the dean of students; homeroom teacher; parents; and students. The success of character education program in Vocational High School is determined by the establishment of the "golden triangle of communication" which is the common awareness and commitment between: school; parents; and students. In addition, daily and weekly evaluation and supervision allows the school, particularly guidance and counseling teacher to identify, anticipate and respond to the indication of behavior and character issues of the students in an appropriate manner. From the results of the research, the board of Vocational High School is recommended to develop a character education system collaboratively with school counselor; dean of students; parents; and students.
\end{abstract}

Keywords: the role of guidance and counseling; collaboration; commitment; character education in vocational school

\begin{abstract}
Abstrak: Penelitian ini bertujuan mendeskripsikan peran bimbingan dan konseling (BK) dalam penguatan pendidikan karakter siswa Sekolah Menengah Kejuruan (SMK) Mitra Industri MM2100, Cikarang, Bekasi, Jawa Barat. Penelitian ini menggunakan pendekatan kualitatif dengan desain studi kasus, dimana data dikumpulkan dengan teknik wawancara dan observasi. Informan utama adalah: pengurus Yayasan Mitra Industri Cikarang; kepala sekolah; wakil kepala sekolah bidang kurikulum; wakil kepala sekolah bidang kesiswaan; guru BK; guru wali kelas; dan siswa SMK Mitra Industri MM2100. Data dianalisis dengan kategorisasi dan reduksi data sesuai dengan fokus penelitian. Hasil penelitian menunjukkan bahwa BK memiliki peran penting dalam penguatan pendidikan karakter. BK berperan aktif dalam proses seleksi; pencegahan perilaku menyimpang; dan pengentasan penyimpangan perilaku siswa. Peran tersebut dilaksanakan secara kolaboratif dengan kesiswaan; guru wali kelas; orangtua; dan siswa. Keberhasilan program pendidikan karakter di SMK dikarenakan terbangunnya "segitiga emas komunikasi" yaitu kesadaran dan komitmen bersama antara: sekolah; orangtua dan siswa. Di samping itu, pola evaluasi dan supervisi harian serta mingguan membuat sekolah, khususnya guru BK dapat mengidentifikasi, mengantisipasi dan merespon indikasi masalah perilaku dan karakter siswa secara cepat. Dari hasil penelitian, para pimpinan SMK disarankan agar mengembangkan sistem pendidikan karakter secara kolaboratif antara guru BK; kesiswaan; orangtua dan siswa.
\end{abstract}

Kata kunci: peran BK; kolaborasi; komitmen; penguatan pendidikan karakter 


\section{PENDAHULUAN}

Pendidikan karakter merupakan agenda pendidikan nasional yang diwujudkan dalam program penguatan pendidikan karakter (Kemdikbud, 2017). Dalam konteks revolusi industri 4.0, kebijakan pendidikan karakter sangat relevan karena karakter menjadi penentu keberhasilan individu dalam menghadapi tantangan hidup (Lickona, 2009). Sementara itu, dalam konteks dunia kerja, karakter menjadi salah satu prasyarat diterimanya pencari kerja dalam proses rekrutmen tenaga kerja di samping kompetensi (Budiman, 2019). Karena itu, maka gerakan penguatan pendidikan karakter perlu digalakkan semua pihak, terutama SMK yang merupakan ujung tombak penyiapan tenaga kerja terampil usia muda andalan Indonesia. SMK perlu memacu kualitas pelaksanaan pendidikan karakter demi menyadari bahwa karakter unggul merupakan modal kesuksesan personal; karier; dan sosial.

Sebagai bagian penting dalam sistem satuan pendidikan, BK perlu mengambil peran dalam pendidikan karakter bersama semua personil pendidikan di sekolah. Guru BK melalui layanan BK perlu mengarahkan orientasi layanan pada pembentukan karakter positif siswa. Intensitas peran BK dalam pendidikan karakter sangat diperlukan karena pada hakikatnya layanan BK berorientasi pada pengembangan karakter positif siswa sehingga mencapai kemaslahatan siswa. Penguatan pendidikan karakter di SMK bersifat urgen dan segera, hal tersebut disebabkan munculnya berbagai kasus perilaku amoral dan asusila sejumlah pelajar SMK. Berbagai kasus problematika perilaku siswa SMK tersebut tentu bersifat kontra produktif dengan dengan tuntutan dunia kerja dan dunia industri yang hanya memberi kesempatan kerja pada pribadi yang berkarakter unggul dan siap kerja. Karena itu, maka upaya pendidikan karakter yang bersifat pencegahan atau preventif dan perbaikan atau kuratif sangatlah diperlukan.

Kajian mengenai peran BK dalam meningkatkan berbagai aspek akademik dan non akademik siswa telah banyak dilakukan (Bolu-Steve \& Oredugba, 2017; Epstein \& Van Voorhis, 2010; Holland, 2015; Kimotho, Njoka, \& Gitumu, 2011; Mau, Li, \& Hoetmer, 2016; Nduta \& Gichuho, 2015; Onyango, Aloka, \& Raburu, 2018; Petra \& Jasna, 2017; Ruff, 2011; Salgong, Ngumi, \& Chege, 2016). Implementasi pendidikan karakter siswa SMK memerlukan pendekatan dan strategi yang tepat sesuai dengan karakter belajar masyarakat Indonesia. Salah satu pendekatan yang perlu diterapkan adalah pendekatan praktik baik dari sebuah satuan pendidikan SMK yang telah sukses menerapkan pengembangan karakter siswa. Praktik baik berupa kisah sukses tersebut akan mampu menjadi inspirasi bagi SMK lain di seluruh Indonesia. Pendekatan praktik baik pelaksanaan pendidikan karakter di beberapa SMK di berbagai daerah yang telah berhasil menerapkan pendidikan karakter melalui proses pendidikan dan pembelajarannya dipandang paling sesuai mengingat deskripsi dan visualisasi praktik baik pendidikan karakter akan memudahkan semua SMK untuk mempelajari, mengimitasi dan menerapkan sesuai konteks sekolah masing-masing. Konsep praktik baik diharapkan mempercepat implementasi pendidikan karakter secara massive di berbagai daerah di Indonesia.

Secara teoretik, BK memiliki peran strategis dalam penguatan pendidikan karakter di sekolah. Peran tersebut dapat diwujudkan melalui makna hakikat layanan dan realisasi program dan layanan BK. Hakikat layanan BK adalah suatu proses bantuan yang diberikan kepada individu siswa secara sistematis dan berkelanjutan oleh seorang ahli yang telah mendapatkan pelatihan khusus, agar individu yang dibantu dapat memahami diri dan lingkungannya, mengarahkan diri, menyesuaikan diri dan mengembangkan potensi yang dimilikinya secara optimal, sesuai dengan nilai-nilai yang dianut, untuk mewujudkan kesejahteraan diri dan masyarakat (Bruce \& Stone, 1981; Gysbers \& Henderson, 1997; Romlah, 2013). Berdasarkan definisi tersebut, dapat diketahui bahwa tujuan bimbingan yaitu agar siswa mampu memahami diri dan lingkungannya, mampu mengarahkan diri, menyesuaikan diri serta mengembangkan potensi yang dimiliki, mampu merencanakan masa depan hingga mencapai kemaslahatan dan kesejahteraan hidup.

BK memiliki fungsi: preventif; pengembangan; dan pengentasan atau kuratif. Tiga fungsi tersebut terwujud dalam struktur program dan kegiatan BK. Saat ini terjadi perubahan paradigma pendekatan BK dari pendekatan yang berorientasi tradisional, remediatif, klinis, dan terpusat pada konselor, beralih ke pendekatan yang berorientasi perkembangan dan pencegahan. Perubahan paradigma ini berimplikasi langsung pada pelaksanaan program BK. Dalam latar pendidikan formal di sekolah, implementasi BK bertujuan memfasilitasi perkembangan potensi konseli, meliputi aspek: pribadi; sosial; belajar; dan karier. Untuk itu, layanan BK dikembangkan sesuai fitrah manusia sebagai makhluk yang berdimensi biologis; psikis; sosial; dan spiritual (ABKIN, 2007). Hakikat dan fungsi layanan BK diwujudkan dalam 
program yang dikembangkan sesuai kebutuhan siswa dalam empat komponen program pelayanan, yaitu: pelayanan dasar; pelayanan responsif; perencanaan individual dan dukungan sistem. Pelayanan BK dapat diberikan melalui pendekatan individual dan pendekatan kelompok. Pendekatan kelompok meliputi: konseling kelompok; bimbingan kelompok; dan bimbingan klasikal. Pendekatan individual berupa konseling individual dan konsultasi. Kegiatan konseling cenderung bersifat kuratif dan menjadi bagian dari komponen layanan responsif sedangkan bimbingan kelompok dan bimbingan klasikal lebih bersifat pencegahan dan pengembangan serta merupakan bagian layanan preventive dan development.

Layanan BK pada prinsipnya dilaksanakan secara kolaboratif bersama dengan komponen sekolah yang lain. Penelitian ini bertujuan mendeskripsikan dan memahami peran BK dalam penguatan pendidikan karakter di SMK Mitra Industri MM2100 Cikarang, Bekasi, Jawa Barat. Latar penelitian merupakan sekolah kejuruan berbasis industri yang didirikan pada tahun 2012 dan dipandang berhasil membentuk karakter siswa dengan lima nilai utama yaitu: jujur; tanggung jawab; disiplin; kerjasama; dan peduli. Dengan keunggulan tersebut, seratus persen siswa SMK ini diterima bekerja di dunia industri sebelum menyelesaikan studinya.

\section{METODE}

Untuk mencapai tujuan penelitian yaitu mendeskripsikan dan memahami peran BK dalam penguatan pendidikan karakter di SMK Mitra Industri MM2100 Cikarang Bekasi Jawa Barat, maka dipilihlah pendekatan kualitatif dengan desain studi kasus. Pemilihan tersebut dimaksudkan agar pengumpulan dan pengkajian data kata-kata serta gambaran peran BK dalam proses pendidikan karakter di latar penelitian dapat dilakukan dengan baik melalui kajian mendalam (Bogdan \& Biklen, 1989).

Latar penelitian adalah SMK Mitra Industri MM2100 yang dikelola Yayasan Mitra Industri Mandiri sejak 19 Februari 2011. SMK ini berada di kawasan industri Cikarang, Jl. Kalimantan Blok DD1-1 Kawasan Industri MM2100 Kabupaten Bekasi Jawa Barat dan berada diatas lahan seluas 9 Ha. Dengan visi menjadi pusat pendidikan dan pengembangan yang mencetak siswa sesuai dengan kebutuhan industri dan berjiwa wirausaha, sekolah ini menanamkan lima nilai utama sekolah yaitu: jujur; tanggung jawab; disiplin; kerjasama; dan peduli yang dipandang selaras dengan kebutuhan dunia industri; dunia kerja; dan dunia usaha.

Data yang dikumpulkan berupa paparan dan penjelasan tentang konsep dan proses penguatan pendidikan karakter serta peran BK di dalamnya. Pengumpulan data dilakukan dengan teknik wawancara mendalam dan observasi non partisipatori. Peneliti hadir ke lokasi acara untuk melakukan wawancara dan mengamati sejumlah kegiatan penguatan pendidikan di SMK Mitra Industri MM2100. Informan utama yang diwawancarai yaitu: pengurus Yayasan Mitra Industri Cikarang; kepala sekolah; wakil kepala sekolah bidang kurikulum; wakil kepala sekolah bidang kesiswaan; guru BK; guru wali kelas dan siswa SMK Mitra Industri MM2100. Reduksi dan analisis data dilakukan dengan kategorisasi sesuai tujuan atau fokus penelitian Bogdan (Bogdan \& Biklen, 1989; Spradley, 2016).

\section{HASIL}

Pendidikan karakter di SMK Mitra Industri MM2100 dibangun secara komprehensif melalui: penataan kurikulum; pengembangan program sekolah; serta penegakan kedisiplinan yang konsisten dan tegas. Program tersebut dilaksanakan secara berkesinambungan dan kolaboratif sejak masa orientasi siswa baru; selama proses pembelajaran; dan kegiatan di luar sekolah. Pihak sekolah secara umum bertanggung jawab terhadap pelaksanaan pendidikan karakter di sekolah, sedangkan orangtua menjadi penanggung jawab di luar sekolah. Pihak sekolah yang terlibat aktif adalah: kepala sekolah; wakil kepala sekolah bidang kesiswaan; wali kelas dan guru BK. Semua peran dan aktivitas layanan BK yang diberikan dan dilaksanakan oleh guru BK merupakan cerminan dari peran BK.

Kepala sekolah menjadi pengarah dan penanggung jawab semua kegiatan pendidikan dan pembelajaran di sekolah ini. Sekolah memberikan kewenangan kepada tim bidang kesiswaan yaitu: wakil kepala sekolah bidang kesiswaan dibantu kepala bidang kedisiplinan; guru wali kelas; dan guru BK sebagai pelaksana utama penguatan pendidikan karakter. Semua elemen penting ini memberikan 
penguatan pendidikan karakter, mendampingi dan memantau aktivitas siswa, baik di dalam sekolah maupun di luar sekolah. Sementara itu, orangtua dan wali siswa menjadi pendamping dan model perilaku berkarakter bagi siswa di luar sekolah.

SMK Mitra Industri MM2100 memiliki keunikan pola pendidikan karakter berupa pola komunikasi sekolah, siswa dan orangtua yang disebut dengan segitiga emas komunikasi. Pola ini dibangun dengan cara melibatkan siswa baru dalam penyusunan komitmen karakter yang dikembangkan dari lima nilai dasar pada masa pendidikan dan latihan siswa baru. Komitmen karakter meliputi komitmen karakter siswa ideal; guru ideal; dan orangtua ideal. Komitmen karakter diikrarkan siswa di hadapan orangtua siswa. Poin-poin tersebut juga diikrarkan guru dan orangtua di hadapan siswa. Dalam implementasinya, pimpinan sekolah dan orangtua saling bekerjasama dalam memantau implementasi komitmen karakter siswa secara berkala melalui pola komunikasi segitiga emas yang digambarkan pada gambar 1 .

Realisasi komitmen siswa dikelola melalui penerapan poin. Setiap siswa baru memperoleh seratus poin sebagai jaminan dan diharapkan tidak berkurang. Sekolah menetapkan ketentuan jenis-jenis pelanggaran berikut konsekuensi pengurangan poin untuk setiap jenis pelanggaran. Salah satu aturan yang perlu diperhatikan oleh siswa adalah apabila terjadi pelanggaran yang mengakibatkan pengurangan hingga dua puluh lima poin, maka siswa akan menerima surat peringatan awal dari sekolah. Siswa yang menerima surat peringatan akan menerima sanksi berupa tidak diperkenankan mengikuti praktik di perusahaan besar. Sanksi ini sering kali menyebabkan permasalahan pada kondisi psikologis siswa.

Secara rinci, pendidikan karakter dalam kegiatan sekolah dilaksanakan pada hari Senin hingga Jumat, selama pelaksanaan pendidikan dan pembelajaran dari pukul 06.45 hingga 16.00 WIB. Selama masa belajar di sekolah, siswa mengikuti kegiatan pembelajaran dan kegiatan sekolah yang bertujuan membentuk karakter positif. Siswa wajib mengikuti apel pagi mulai pukul 06.45 hingga 07.30 WIB. Dari pengamatan, diperoleh data bahwa siswa dilatih untuk sigap, siap dan memiliki stamina yang baik. Menjelang jam apel, petugas kedisiplinan memantau ketepatan waktu hadir siswa. Siswa yang terlambat akan dikenai konsekuensi memakai rompi oranye dan berdiri pada barisan tersendiri. Dalam kegiatan harian, wali kelas banyak berperan secara langsung. Wali kelas bertugas melakukan pemantapan pemahaman dan sikap siswa terhadap kebiasaan berperilaku disiplin, sekaligus menjadi pendamping dan pengawas pelaksanaan pendidikan karakter di kelas, di sekolah dan di luar sekolah. Setiap hari diawal kegiatan pembelajaran, wali kelas melakukan pembinaan karakter selama empat puluh menit. Pembinaan karakter tersebut meliputi: verifikasi ketidakhadiran dan mengindentifikasi info tentang kebutuhan siswa, khususnya mengenai masalah mengenai pembelajaran. Selanjutnya, wali kelas selalu berkomunikasi dengan bidang kedisiplinan dan orangtua siswa untuk memantau perkembangan karakter siswa. Wali kelas juga selalu berkoordinasi dan berkolaborasi dengan guru BK dalam mendampingi serta membimbing siswa yang bermasalah.

Tugas guru BK dalam pelaksanaan pendidikan karakter di SMK Mitra Industri MM2100 terfokus pada penerimaan siswa baru; pemberian layanan BK pada siswa yang bermasalah; dan penyiapan lulusan. Dalam seleksi siswa baru, guru BK menjadi tim seleksi siswa baru dan tim sosialisasi aturan sekolah pada calon siswa baru dan orangtua siswa baru. Dalam proses seleksi siswa baru, guru BK bertugas mewawancarai setiap pendaftar secara intensif. Pada tahap ini, guru BK bersama tim Yayasan Mitra Industri mengidentifikasi minat dan motivasi setiap pendaftar sekaligus mengidentifikasi potensi calon siswa untuk selanjutnya membantu siswa dalam menentukan pilihan bidang keahlian secara tepat sesuai potensinya. Guru BK mendalami motivasi dan alasan siswa memilih SMK ini, apakah karena

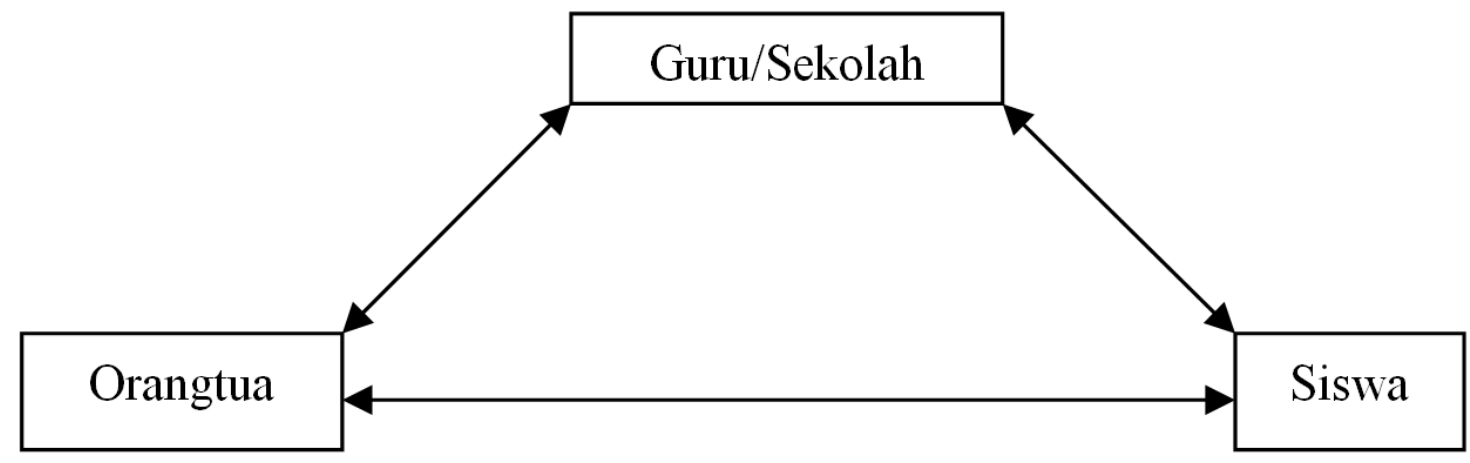

Gambar 1. Segitiga Emas Komunikasi SMK Mitra Industri MM2100 
minat orangtua ataukah minat pribadi siswa. Hanya pendaftar dengan motivasi intrinsik kuat yang akan diterima. Teknik wawancara merupakan teknik utama dalam seleksi siswa baru di SMK Mitra Industri MM2100 karena dipandang sebagai teknik yang paling tepat dan akurat untuk mendalami motivasi serta minat karier setiap calon siswa. Kepala SMK Mitra Industri MM2100 menyatakan bahwa teknik ini terbukti efektif dalam menyeleksi pendaftar yang memiliki motivasi intrinsik kuat; minat karier yang terarah; dan mengidentifikasi kecenderungan kebiasaan positif.

Dalam pendampingan karakter siswa, guru BK bermitra dengan wali kelas. Guru BK harus selalu siap menerima alih tangan atau referal dari wali kelas setiap hari. Sesuai prosedur kerja, wali kelas harus menindaklanjuti masalah siswa yang ditemukan. Wali kelas akan merekam data permasalahan siswa dan mengkomunikasikannya dengan guru BK. Guru BK menindaklanjutinya dengan layanan konseling individual; konseling kelompok; bimbingan klasikal dan bimbingan kelompok. Guru BK memang tidak memiliki jadwal khusus untuk masuk kelas secara rutin, namun diperkenankan meminta jam untuk melaksanakan layanan bimbingan di sebuah kelas secara kolaboratif dengan wali kelas. Dengan pola ini, jumlah kunjungan siswa ke ruang BK untuk memperoleh layanan konseling juga cukup tinggi.

Guru BK juga berkolaborasi dengan seluruh tim sekolah dalam melakukan evaluasi melalui rapat mingguan. Jika ditemukan pelanggaran oleh siswa, guru BK bersama wali kelas dan bidang kedisiplinan bertugas melakukan pendalaman kasus dengan mewawancarai siswa untuk menetapkan berita acara pelanggaran. Dalam konteks sekolah ini, ditetapkan bahwa BK tidak boleh membela siswa namun wajib mengikuti aturan tata tertib. Ketika siswa melakukan pelanggaran, aturan tetap harus ditegakkan. Siswa harus menerima hukuman atas perbuatannya.

Peran guru BK yang tidak kalah pentingnya adalah pemberian layanan konseling bagi siswa yang mengalami masalah karena melakukan pelanggaran. Siswa yang dikenai sanksi pengurangan poin karena pelanggaran biasanya akan mengalami kecemasan dan stress. Hal itu dikarenakan pengurangan poin akan berakibat pada penundaan promosi di perusahaan tertentu, juga dapat mengurangi kesempatan berkarier di perusahaan atau instansi. Dalam pemberian layanan bagi siswa yang dikenai sanksi, guru BK bertugas mendampingi dan memberikan pemahaman agar siswa menyadari konsekuensi perilakunya. Dengan demikian, diharapkan siswa dapat lebih menerima kenyataan berupa hukuman secara sportif. Setelah proses konseling, guru BK dan wali kelas akan selalu berkoordinasi secara rutin seminggu sekali untuk memantau perkembangan psikologis dan perilaku siswa agar tetap optimis, semangat dan berusaha untuk bangkit menjadi lebih baik. Secara umum, guru BK melaporkan kinerjanya dalam kegiatan evaluasi dan koordinasi mingguan yang dihadiri pimpinan sekolah dan wali kelas.

\section{PEMBAHASAN}

Dalam paparan data, digambarkan bahwa guru BK di SMK Mitra Industri MM2100 berperan memberikan layanan BK dan melakukan pendampingan pada siswa secara kolaboratif dengan guru wali kelas dan bidang kesiswaan. Jika dikaji berdasarkan pandangan Bruce \& Stone (1981); Gysbers \& Henderson (2001); dan Gysbers \& Henderson (1997) maka semua peran yang ditunaikan oleh guru BK SMK Mitra Industri MM2100 berorientasi memenuhi fungsi preventif atau pencegahan perilaku negatif, fungsi developmental atau pengembangan karakter positif siswa dan fungsi kuratif atau pengentasan masalah. Fungsi pencegahan dan pengembangan diterapkan melalui penanaman nilai-nilai pada siswa yang diorientasikan dapat mencegah munculnya perilaku negatif.

Peran guru BK dalam penguatan pendidikan karakter di sekolah menjadi lebih intensif karena guru BK bekerja secara kolaboratif dengan semua komponen sekolah, khususnya wali kelas. Dukungan sekolah berperan signifikan karena kinerja kolaboratif sangat menentukan keberhasilan program BK. Kinerja kolaboratif memang disarankan agar layanan BK komprehensif terlaksana dengan baik, efektif, dan mendukung tercapainya pembentukan karakter dan perilaku positif siswa (Gysbers \& Henderson, 2001).

Selaras dengan hasil penelitian ini, sebuah penelitian di Kenya menunjukkan bahwa eksistensi BK memiliki pengaruh signifikan dalam mengembangkan perilaku disiplin dan perilaku positif siswa sekolah menengah (Onyango dkk., 2018). Sedemikian pentingnya peran BK di sekolah sehingga lemahnya peran BK akan membuat upaya pengembangan perilaku positif dan disiplin siswa tidak terlaksana dengan baik (Salgong dkk., 2016). Dengan kata lain, eksistensi BK sangat penting artinya dalam upaya mencegah perilaku negatif siswa. Sementara itu, penelitian lain menyebutkan bahwa peningkatan perilaku disiplin 
di suatu lembaga pendidikan akan mengalami kendala ketika peran BK kurang maksimal dan upaya kolaborasi BK dengan pengelola pendidikan lainnya tidak terjalin dengan baik (Nduta \& Gichuho, 2014). Jika ditelaah melalui perspektif hasil penelitian Salgong dkk. (2016), maka SMK Mitra Industri MM2100 dapat dipandang telah melakukan upaya yang tepat dengan memposisikan BK sesuai peran melalui kinerja kolaboratif.

Guru BK memiliki peran signifikan dalam mengembangkan perilaku positif siswa melalui upaya bimbingan dan pemberian harapan positif (Mau dkk., 2016). Penempatan posisi dan peran guru BK sebagai pemberi harapan juga tampak dalam sistem pendidikan karakter di SMK Mitra Industri MM2100, di mana guru BK melalui intervensi konseling mendampingi proses penegakan disiplin pada siswa yang harus menerima konsekuensi ketika melakukan pelanggaran.

Masih terkait dengan peran BK dalam sistem pendidikan, Bolu-Steve \& Oredugba (2017) menyebutkan bahwa BK memiliki peran penting dalam mencapai keberhasilan akademik dan kemampuan psikososial. Jika ditelaah melalui pendapat ini, maka tim BK SMK Mitra Industri MM2100 telah berupaya menjalankan perannya dalam mendukung siswa mencapai keberhasilan akademik khususnya dalam mempersiapkan diri memasuki dunia kerja.

Sebuah hasil penelitian menunjukkan adanya peningkatan kebutuhan akan layanan BK dalam mengembangkan karakter positif di siswa sekolah menengah di Kenya (Kimotho dkk., 2011). Di sisi lain, layanan BK akan mendapatkan penerimaan yang baik oleh siswa apabila guru BK mampu menciptakan kepercayaan siswa terhadap konselor (Holland, 2015). Temuan penelitian Kimotho dkk. (2011) membuktikan bahwa layanan BK memiliki peran penting dalam mencapai tujuan pendidikan karakter, sedangkan penelitian Holland (2015) mengindikasikan bahwa dalam menjalankan perannya, guru BK perlu membentuk dan menjaga kepercayaan siswa. Hasil kajian di SMK Mitra Industri MM2100 ini menunjukkan tren serupa, di mana BK memiliki peran penting dalam pembentukan karakter positif siswa sekaligus mampu meraih kepercayaan siswa sehingga siswa selalu memadati layanan konseling yang disediakan guru BK SMK MM2100.

Membimbing dan mendampingi siswa dalam penguatan karakter bukan saja tanggung jawab peran layanan BK, melainkan tanggung jawab yang harus diemban secara kolaboratif. Hal ini menegaskan bahwa upaya BK harus dikembangkan dengan melibatkan peran seluruh komponen sekolah, termasuk: kepala sekolah; guru; dan orangtua (Gysbers \& Henderson, 2014). Pengelolaan bersama secara intensif menjadi salah satu isu penting yang perlu diperhatikan oleh pengembang dan pelaksana program BK di sekolah. Jika merujuk pada pandangan Gysbers \& Henderson, dapat dipahami bahwa SMK Mitra Industri MM2100 telah menerapkan pola kerja tersebut, dan irama kerja sedemikianlah yang membuat SMK ini dipandang berhasil membentuk karakter positif.

Kinerja kolaboratif sangat diperlukan dalam menyukseskan program BK (Epstein \& Van Voorhis, 2010). Sesuai dengan komitmen SMK Mitra Industri MM2100 dalam mengembangkan segitiga emas komunikasi dimana guru BK terlibat aktif dalam penguatan pendidikan karakter melalui kolaborasi bersama guru dan orangtua seolah menjadi jawaban dari temuan penelitian Gregorcic-Mrvar \& Mazgon (2017) yang mengkaji sejumlah problematika guru BK di Slonevia dalam membangun kolaborasi dengan orangtua dan berbagai komunitas. Dengan dukungan dari sekolah, guru BK SMK Mitra Industri MM2100 mampu mengembangkan jalinan kolaborasi dengan orangtua dan lembaga mitra guna mengembangkan karakter positif. Kinerja kolaborasi inilah yang menjadi salah satu kunci keberhasilan sekolah dalam menguatkan lima karakter utama siswa.

Guru BK harus bekerja secara akuntabel agar proses dan hasil layanannya dapat diketahui oleh berbagai pihak terkait (Ruff, 2011). Kinerja guru BK di latar penelitian jika diulas melalui pendapat Ruff (2011) merupakan wujud realisasi peran BK yang akuntabel dalam mengembangkan aspek psikososial siswa. Perspektif tersebut tidaklah berlebihan mengingat guru BK di SMK Mitra Industri MM2100 berperan mendampingi siswa melalui layanan BK agar mereka mampu menentukan rencana kariernya dan memberikan penguatan psikologis ketika siswa menjalani konsekuensi perilakunya.

Peran BK dalam penguatan pendidikan karakter di SMK Mitra Industri MM2100 tidak lepas dari kebijakan manajemen sekolah. Hal ini dikarenakan dukungan iklim organisasi menjadi salah satu penentu kinerja BK yang baik. Dukungan iklim organisasi yang baik sangat mendukung kinerja BK mengingat guru BK memerlukan dukungan agar mereka merasa yakin atau memiliki self-efficacy yang baik dalam bekerja dan melayani kebutuhan siswa (Haron, Jaafar, \& Baba, 2010). Dukungan iklim organisasi menjadi salah satu penentu kinerja BK yang baik. Jika ditelaah dari pendapat Wangid (2010), 
maka pola pendidikan karakter yang diterapkan di SMK Mitra Industri MM2100 dapat dikategorikan sebagai model pendidikan karakter gabungan. Dalam model ini, dilakukan penggabungan antara model pendidikan karakter terintegrasi dengan bidang studi dan model pendidikan karakter di luar rumah.

Di antara wujud kinerja BK SMK Mitra Industri MM2100 yang dipandang berhasil, terdapat beberapa keterbatasan yang perlu dicermati bersama. Salah satunya adalah tidak adanya program BK yang diterapkan secara reguler sesuai kerangka kerja BK komprehensif. Indikator yang paling nyata adalah tidak adanya jadwal BK masuk kelas secara reguler. Karena kebijakan sekolah tersebut, maka guru BK cenderung mengembangkan rencana layanan yang bersifat pendampingan masalah, lalu guru BK mengembangkan kegiatan bimbingan dan melakukan konseling jika diperlukan. Jika dipandang dengan perspektif kebijakan pemerintah dan kajian BK menurut Gysbers \& Henderson (2001), kebijakan SMK Mitra Industri MM2100 masih belum menerapkan BK yang ideal. Seharusnya SMK Mitra Industri MM2100 menindaklanjuti semua kebutuhan dan permasalahan siswa dengan menerapkan BK komprehensif. Setiap guru BK perlu mengembangkan program BK komprehensif yang memiliki empat komponen layanan yaitu: komponen layanan dasar atau kurikulum bimbingan; layanan responsif; layanan perencanaan individual; dan dukungan sistem (Gysbers \& Henderson, 2001). Empat komponen tersebut akan menjadikan layanan BK lebih efektif dan terarah sesuai kebutuhan siswa.

\section{SIMPULAN}

Guru BK di SMK Mitra Industri MM2100 mampu menunjukkan peran aktif BK dalam penguatan pendidikan karakter di sekolah melalui kinerja pemetaan minat karier dan pendampingan siswa yang memerlukan layanan BK berdasarkan rekomendasi dan pelimpahan dari wali kelas. Layanan bimbingan dilakukan melalui bimbingan klasikal; bimbingan kelompok; dan konseling bagi siswa yang menjalani sanksi akibat pelanggaran. Guru BK juga berkolaborasi dengan wali kelas, kesiswaan dan orangtua. Untuk meningkatkan peran BK yang lebih banyak pada layanan responsif, SMK Mitra Industri MM2100 disarankan untuk meningkatkan kualitas dan peran layanan BK melalui pengembangan dan implementasi program BK komprehensif. Kualitas layanan dapat ditingkatkan melalui penjadwalan layanan bimbingan klasikal dan kelompok secara reguler. Program dan implementasi program sedemikian untuk memenuhi kebutuhan dan merespon permasalahan siswa melalui program dan layanan sistematis dan reguler sesuai struktur BK komprehensif tanpa meninggalkan kekhasan program pendidikan SMK Mitra Industri MM2100.

\section{DAFTAR RUJUKAN}

ABKIN. (2007). Rambu-Rambu Penyelenggaraan Bimbingan dan Konseling dalam Jalur Pendidikan Formal. Bandung: ABKIN.

Bogdan, R. C., \& Biklen, S. K. (1989). Qualitative Research for Education, An Introduction to Theory and Methods. Boston: Allyn and Bacon, Inc.

Bolu-Steve, F., \& Oredugba, O. O. (2017). Influence of Counselling Services on Perceived Academic Performance of Secondary School Students in Lagos State. International Journal of Instruction, 10(2), 211-228.

Bruce, S., \& Stone, S. C. (1981). Fundamentals of Guidance. Boston: Houghton Mifflin.

Budiman, A. (2019). Masukan Pedoman PPK Direktorat PSMK. Jakarta: Kemdikbud.

Epstein, J., \& Van Voorhis, F. (2010). School Counselors' Roles in Developing Partnerships with Families and Communities for Student Success. Professional School Counseling, 14(1), 1-14. https://doi.org/10.5330/ prsc.14.1.m6070358408g9227

Gregorcic-Mrvar, P., \& Mazgon, J. (2017). The Role of The School Counsellor in School-Community Collaboration: The Case of Slovenia. International Journal of Cognitive Research in Science, Engineering and Education, 5(1), 19-29. https://doi.org/10.5937/IJCRSEE1701019G

Gysbers, N. C., \& Henderson, P. (2001). Leading and Managing Comprehensive School Guidance Programs. ERIC Clearinghouse on Counseling and Student Service.

Gysbers, N. C., \& Henderson, P. (2014). Developing and Managing Your School Guidance and Counseling Program. John Wiley \& Sons.

Gysbers, N. C., \& Henderson, P. (1997). Comprehensive Guidance Programs that Work-II. ERIC. 
Haron, S., Jaafar, W. M. W., \& Baba, M. (2010). The Influence of School Climate Towards Counselor's SelfEfficacy. Procedia-Social and Behavioral Sciences, 5, 445-448.

Holland, M. M. (2015). Trusting Each Other: Student-Counselor Relationships in Diverse High Schools. Sociology of Education, 88(3), 244-262.

Kemdikbud. (2017). Panduan Penguatan Pendidikan Karakter pada Jenjang Pendidikan Dasar. Jakarta: Kemdikbud.

Kimotho, F. W., Njoka, J. N., \& Gitumu, M. W. (2011). Impact of Guidance and Counseling Services on Students' Discipline a Case of Public Secondary Schools in Eastern kenya. Kenya Journal of Educational Planning Economics and Management, 11(1).

Lickona, T. (2009). Educating for Character: How Our Schools Can Teach Respect and Responsibility. Bantam.

Mau, W.-C. J., Li, J., \& Hoetmer, K. (2016). Transforming High School Counseling: Counselors' Roles, Practices, and Expectations for Students' Success. Administrative Issues Journal: Connecting Education, Practice, and Research, 6(2), 83-95.

Nduta, M. M., \& Gichuho, C. M. (2014). The Role of Guidance and Counselling in Curbing Student Indiscipline in Secondary Schools in Kambaa Division, Kiambu County, Kenya. International Journal of Science and Research (IJSR), 3(9), 790-793.

Nduta, M. M., \& Gichuho, C. M. (2015). Stakeholders Involvement and Perception towards Guidance and Counselling in Kambaa Division Secondary Schools, Kiambu County, Kenya. International Journal of Science and Research (IJSR), 4(1), 186-188.

Onyango, P. A., Aloka, P. J., \& Raburu, P. (2018). Effectiveness of Guidance and Counseling in the Management of Student Behaviour in Public Secondary Schools in Kenya. International Journal of Applied Psychology, $8(1), 6-11$.

Petra, G. M., \& Jasna, M. (2017). The Role of The School Counsellor in School-Community Collaboration: The Case of Slovenia. International Journal of Cognitive Research in Science, Engineering and Education, 5(1), $1-29$.

Romlah, T. (2013). Teori dan Praktek Bimbingan Kelompok. Malang: Universitas Negeri Malang.

Ruff, R. R. (2011). School Counselor and School Psychologist Perceptions of Accountability Policy: Lessons from Virginia. The Qualitative Report, 16(5), 1270-1290.

Salgong, V. K., Ngumi, O., \& Chege, K. (2016). The Role of Guidance and Counseling in Enhancing Student Discipline in Secondary Schools in Koibatek District. Journal of Education and Practice, 7(13), 142-151.

Spradley, J. P. (2016). The Ethnographic Interview. Waveland Press.

Wangid, M. N. (2010). Peran Konselor Sekolah dalam Pendidikan Karakter. Jurnal Cakrawala Pendidikan, 1(3), $173-186$. 